\title{
Two-Phase Slug Flow Correlations for Severe Slugging in Subsea Pipelines
}

\author{
L.C. Igbokwe, G.F. Naterer ${ }^{*}$, S. Zendehboudi \\ Faculty of Engineering and Applied Science, Memorial University, St. John's, Canada \\ *gnaterer@mun.ca
}

\begin{abstract}
Slug flows in multiphase petroleum fluids may present substantial challenges to the economical and safe operation of equipment used for oil recovery, flow separation and stabilization. Two-phase slug flow parameters provide key information in the design of downstream separation installation, particularly in slug dominated flows. In this paper, a dimensionless analysis based on the Buckingham pi theorem will be used to develop and analyze new slug velocity correlations. The empirical model uses relevant dimensionless numbers including the Reynolds number, Bejan number, and the density ratio. The new model can be used in the selection of operating conditions and secondary recovery mechanisms. Over 5,000 data points were used for the analysis, covering choke openings between 10 and 100 percent, and Reynolds numbers between 150 and 400 . The dimensionless numbers in the correlations show the dependence of the slug velocity on differential pressure, choke valve opening, and mixture flowrate. The correlation predicts $90 \%$ of the measurements within a $10 \%$ maximum percentage error. The mean absolute deviation of the correlation is about $9 \%$. The model can be applied for low flow rates typical of some flow conditions in subsea pipelines, and choke openings between $10-98 \%$. The correlation can predict the slug velocity and production rates for vertical and catenary riser systems.
\end{abstract}

Keywords- subsea pipelines; severe slugging; dimensionless analysis; two phase flow; oil recovery.

\section{INTRODUCTION}

In multiphase flows in pipelines, the flowrate, temperature, and pressure often oscillate in an irregular manner (Naterer, 2018). In slug flows, these irregular flow oscillations contribute to system instabilities. While the general goal of the oil recovery process is to maximize hydrocarbon extraction at the lowest cost per barrel, slugging, when transporting fluid from the wellhead to surface processing facilities, can jeopardize the economic and safe operation of the oil recovery facilities (Taitel et al., 1990; Pedersen et al., 2017).

Several slugging experiments and numerical investigations in the past have focused on the understanding of flow characteristics and modelling of fluid flow processes to improve process efficiency in offshore flow separation. However, the design of two-phase process facilities can aggravate slugging potential and may diminish anti-slug control measures. The flow speed of slugs through the production system is crucial in topside process facilities and it is required as an input parameter for mechanistic models and operating equipment. Therefore, an accurate prediction of slug velocity is important for reliable flow characterization, and selection and design of appropriate mitigation methods. Although there are several past research studies about slug flows in conventional horizontal and inclined pipelines, few studies have been performed to predict a severe slugging velocity, related to flow assurance challenges in offshore petroleum production. In this paper, data analysis from an experimental investigation is presented. It presents results from an air-water (two-phase) flow, pipeline-riser set-up, to develop a slug velocity model with applications to subsea oil and gas pipelines.

\section{MODEl FormUlation}

Experimental studies were conducted in an experimental facility for slug mitigation at the Offshore Energy Laboratory of Aalborg University, Denmark. Details of the experimental apparatus, procedures and results are presented by Igbokwe (2020). A dimensional analysis is performed with this experimental data to obtain an empirical correlation of the slug flow velocity in slug regime dominated flow. The dimensionless $\pi$ terms are formed from the correlation variables based on the Buckingham $\pi$-theorem (Buckingham, 1914). The production flow rate, $W$, is expressed as a function of the nine parameters as follows,

$W_{\text {mix }}=f\left[w_{l, i n}, w_{g, \text { in }} Z, P_{i n}, P_{\text {sep }}, \rho_{m}, \mu_{m}, w_{L i}, D\right]$ 
where $w, Z, P, \rho, \mu$ and $D$ refer to the mass flow rate, riser-top choke opening percentage, pressure, and diameter, respectively. Based on the two-phase flow properties and system geometrical parameters, the identified variables are grouped into appropriate dimensionless groups and shown in Table 1. The Buckingham $\pi$-theorem is used to determine the non-dimensional form of the correlation. Equation (1) can be written in terms of the relevant dimensionless groups as follows:

$\pi_{1}=f\left(\pi_{1}, \pi_{2}, \pi_{3} \ldots \pi_{i}\right)$

The various dimensionless groups are obtained as functions of the parameters that influence slugging in flow systems. The six dimensionless groups were chosen based on past literature, system parameters, and flow variables identified during experiments involving slug creation.

$R e_{m, o}=C_{1} \cdot Z^{n_{1}} R e_{m, i}^{n_{2}} B e_{p}{ }^{{ }^{3} 3} B e_{R}^{n_{4}} B e_{r}{ }^{n_{5}}\left(\frac{\rho_{g}}{\rho_{l}}\right)^{n_{6}}$

In Equation (3), $R e_{m, o}$ is the mixture Reynolds number of fluid flow at the topside; $R e_{m, i}$ represents the Reynolds number determined at inlet of the pipeline; and $B e$ is the Bejan number. The subscripts $p, R, r$, denote the pipeline, riser, and vertical section of the riser respectively. The $\pi$ terms are used to define the dimensionless groups while the exponents are parameters determined from the coefficient of data fit. A logarithmic expansion of Equation (3) gives:

$\log R e_{m, o}=\log C_{1}+n_{1} \log Z+n_{2} \log R e_{m, i}+n_{3} \log B e_{p}+$ $n_{4} \log B e_{R}+n_{5} \log B e_{r}+n_{6} \log \rho_{g} / \rho_{L}$

The Reynolds number in Equation (3) can be expressed directly in terms of the variables of this experiment and the slug flow velocity:

$R e_{m, i}^{*}=\frac{4 v_{m}}{\alpha_{l} \pi \rho_{m} D} \cdot \frac{1}{\mu_{m}}$

Here $v_{m}$ is the mixture interfacial velocity for an oscillating fluid flow; $\rho_{m}$ is the density of the slug; and $D$ is the diameter of the flow path. The mixture interfacial velocity is obtained as $v_{m}=v_{l}+v_{g}$. An analysis is carried out to examine the relationship of the main parameters with the mixture slug velocity. The first step in the analysis evaluates the choke opening, $z$. Equation (5) becomes:

$\log \left(R e_{m, o}{ }^{*}\right)=\log C_{1}+n_{1} \log (Z)$

Through a similar procedure, the inflow rates are evaluated using the Reynolds number in the pipeline while the pressure drop in the pipeline and riser sections are determined using the Bejan number. The phase densities are evaluated using the density ratio, $\frac{\rho_{\mathrm{g}}}{\rho_{\mathrm{l}}}$, determined at the pipeline inlet. Substituting appropriate values, the following equation is obtained:

$R e_{m, o}{ }^{*}=0.934 Z^{-0.076} R e_{m, i}{ }^{-0.061} B e_{R}{ }^{0.249}$

Further iterations are performed on the preliminary correlation to improve the coefficients obtained from previous iterations until they converge. Further iterations of the empirical parameters yield:

$R e_{m, o}{ }^{*}=0.528 Z^{-0.0431} R e_{m, i}{ }^{-0.056} B e_{R}{ }^{0.276}$

The coefficients and exponents in the correlations were determined by performing iterations on the experimental data. Scatter plots were created and evaluated using linear regression on a log-log scale. An iterative procedure was performed on a combination of the various dimensionless groups for the analysis, which included the process variables that affect the slug flow regime.

In the first iteration, a scatter plot of $\log R e_{m, o}{ }^{*} v s \log (Z)$ was created to examine the relationship between the slug velocity and the choke opening. Plots of $\frac{R e_{m, o}{ }^{*}}{Z n_{1}} v s R e_{m, i}{ }^{*}$,

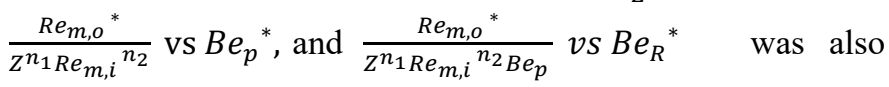
created to evaluate the influences of the gas and liquid inflow rates, pressure drop in the pipeline, and the pressure drop in the riser, respectively. The slopes of the curve fit on the scatter plots provided the coefficients for the general correlation. A minimum of a $15 \%$ R-squared value was taken as the acceptance criterion, before it was considered for further iterations. Approximate coefficients were then obtained from the first iteration, leading to the preliminary equation. The empirical parameters are $\mathrm{n}_{1}=-0.076, \mathrm{n}_{2}=-0.061, \mathrm{n}_{3}=$ $0, \mathrm{n}_{4}=0.02497, \mathrm{n}_{5}=0$, and $\mathrm{n}_{6}=0$.

The constants and R-squared values are shown in Table 2.

Further iterations are conducted to improve the empirical parameters for the model. The empirical correlation, which combines the other dimensionless groups with their coefficients, is utilized to conduct the sensitivity analysis. The second phase of the data analysis investigates the impact of the various dimensionless groups, considered individually, on the overall $\pi$ group combinations. Each of the $\pi$ group's sensitivity analysis is carried out while all other dimensionless numbers are present. Hence, the order in which the $\pi$ groups are combined did not affect the results of the final empirical model. In the following section, sample results from these correlations are presented and discussed.

The workflow and calculation procedure are summarized as follows:

1. The influential slug flow variables are identified and used to obtain the dimensionless numbers based on the Buckingham $\pi$-theorem. They are then used as the input variables for the correlation.

2. The $\pi$ groups are calculated and evaluated against measured flow rates at the choke outlet.

3. Based on the set criterion ( $15 \% \mathrm{R}$-squared value), the approximate coefficients are determined from the slopes of the curve fit in the scatter plots. 
4. Using the experimental data, the coefficients and exponents obtained from iterations are substituted into Equation (3), leading to a preliminary correlation.

5. Further iterations are then conducted on the preliminary equation to determine the empirical parameters with high accuracy and reliability.

6. The final correlation is obtained when convergence is achieved.

\section{RESULTS AND DisCUSSION}

Table 3 summarizes the sensitivity analysis results for each dimensionless group. These were compared with the individual $\pi_{\mathrm{i}}$ groups in the general correlation. Their respective gradients and regression coefficients are also given. After the calculated slug velocity is compared with the experimental data (see Figure 4), the general form of the correlation is $y=a x+b$, where $\mathrm{a}$ is the coefficient of the gradient, $\mathrm{x}$.

Figure 1 shows that a linear relationship exists between the Reynolds number and choke opening. A curve fit for the plot of $\frac{R e_{m, o}{ }^{*}}{z^{n_{1} R e_{m, i}^{n_{2}}}} v s B e_{p}^{*}$ is used for the analysis of the pressure drop in the pipeline section as shown in Table 2 . The value of $R^{2}$ is small, thereby indicating a weak correlation. Therefore, $n_{3}=0$. The effect of the Bejan number in the pipeline was insignificant so it was neglected. Similarly, a small

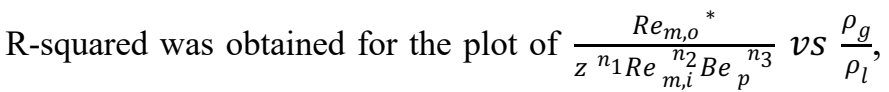
showing that there is little or no correlation between the combined terms and the density ratio. Thus, the density ratio was also neglected in the final correlation; this might be attributed to small variations in the density ratio in different real cases. The pressure drop in the riser (pressure difference between the riser base and the downstream separator) is calculated as the maximum Bejan number. Figures 2 and 3 show the dependence of the slug velocity on the mixture flowrate and differential pressures, respectively. Both the gas and liquid velocities increase as the choke opening increases. The results obtained from the final correlation were also compared to the experimental data at typical choke opening sizes in oil and gas production systems (see Figure 5). It was found that the correlation predicts the slug flow velocity with reasonable accuracy for the various choke sizes. The new correlation performs best for choke openings between $10 \%$ and $45 \%$.

Equation (8) represents the two-phase correlation for predicting the production rate in a slugging offshore pipeline-riser system. The rate term can be derived from the Reynolds number, $w_{m}=\frac{R_{e m}, v_{m}, D}{\rho_{m}}$, where $\mathrm{w}_{\mathrm{m}}$ is the mixture flow rate and $\mathrm{D}$ is the pipeline diameter. The correlation predicts $90 \%$ of the measurements within a $10 \%$ maximum percentage error. The mean absolute deviation of the correlation is about $9 \%$.

\section{CONCLUSIONS}

A new correlation for the slug velocity was presented in this paper. It was shown that the correlation performs well over a wide range of experimental data. The dimensionless numbers to develop the relevant correlations showed the dependence of the slug velocity on differential pressures, choke valve opening, and mixture flowrate. The mean absolute deviation of the correlation is about $9 \%$. The model can be applied to low flow rates typical of flow conditions in subsea pipelines and choke openings between 10-98\%. The correlation can predict slug velocity and production rates for vertical and catenary riser systems. The model can also be applied to a pipeline system with a downward inclination followed by an upward riser.

Table 1. Summary of dimensionless groups for slug velocity in the riser.

\begin{tabular}{|c|c|c|c|}
\hline $\begin{array}{c}\pi \\
\text { term }\end{array}$ & $\begin{array}{c}\text { Dimensionless } \\
\text { group }\end{array}$ & Expression & Description \\
\hline$\pi_{1}$ & $\begin{array}{c}\text { Mixture } \\
\text { Reynolds } \\
\text { number at the } \\
\text { choke outlet, } \\
\operatorname{Re}_{\mathrm{m}, \mathrm{o}}\end{array}$ & $\operatorname{Re}_{m, o}$ & $\begin{array}{l}\text { Ratio of } \\
\text { inertia and } \\
\text { viscous } \\
\text { forces in the } \\
\text { pipeline }\end{array}$ \\
\hline$\pi_{2}$ & $\begin{array}{c}\text { Choke valve } \\
\text { opening }\end{array}$ & $Z$ & $\begin{array}{c}\text { Percentage of } \\
\text { choke } \\
\text { opening }\end{array}$ \\
\hline$\pi_{3}$ & $\begin{array}{c}\text { Mixture } \\
\text { Reynolds } \\
\text { number for flow } \\
\text { in pipeline inlet, } \\
\operatorname{Re}_{\mathrm{m}, \mathrm{i}}\end{array}$ & $\frac{\rho_{m, p} v_{m, p} D_{p}}{\mu_{m}}$ & $\begin{array}{l}\text { Ratio of } \\
\text { inertia and } \\
\text { viscous } \\
\text { forces in the } \\
\text { pipeline }\end{array}$ \\
\hline$\pi_{4}$ & $\begin{array}{l}\text { Bejan number } \\
\text { for flow in the } \\
\text { pipeline, } \mathrm{Be}_{\mathrm{p}}\end{array}$ & $\frac{\Delta P_{p} L_{p}^{2}}{\mu_{m, p} \epsilon_{m, p}}$ & $\begin{array}{l}\text { Dimensionles } \\
\text { s pressure } \\
\text { drop along } \\
\text { the pipeline }\end{array}$ \\
\hline$\pi_{5}$ & $\begin{array}{l}\text { Bejan number } \\
\text { for flow in } \\
\text { riser, } \mathrm{Be}_{\mathrm{r}}\end{array}$ & $\frac{\Delta P_{r} L_{r}^{2}}{\mu_{m, r} \epsilon_{m, r}}$ & $\begin{array}{l}\text { Dimensionles } \\
\text { s pressure } \\
\text { drop along } \\
\text { the riser }\end{array}$ \\
\hline$\pi_{6}$ & $\begin{array}{c}\text { Density ratio, } \\
\text { DR }\end{array}$ & $\frac{\rho_{g}}{\rho_{l}}$ & $\begin{array}{l}\text { Ratio of the } \\
\text { gas density to } \\
\text { the liquid } \\
\text { density }\end{array}$ \\
\hline
\end{tabular}


Table 2. Correlation coefficients for the first iteration.

\begin{tabular}{|c|c|c|c|}
\hline $\begin{array}{l}\text { Dimensionless } \\
\text { group }\end{array}$ & $\mathbf{R}^{2}$ & $\mathbf{a}$ & B \\
\hline $\operatorname{Re}_{\mathrm{m}, \mathrm{o}}{ }^{*} \mathrm{vs} \mathrm{Z}$ & 0.486 & -0.076 & 2.320 \\
\hline$\frac{\operatorname{Re}_{\mathrm{m}, \mathrm{o}}{ }^{*}}{\mathrm{Z}^{\mathrm{n}_{1}}} \mathrm{vs} \mathrm{Re}_{\mathrm{m}, \mathrm{i}}$ & 0.601 & -0.061 & 2.426 \\
\hline$\frac{\operatorname{Re}_{\mathrm{m}, \mathrm{o}}{ }^{*}}{\mathrm{z}^{\mathrm{n}_{1} \operatorname{Re}_{\mathrm{m}, \mathrm{i}}} \mathrm{n}_{2}} \mathrm{vs} \mathrm{Be}$ & 0.012 & -0.125 & 1.386 \\
\hline 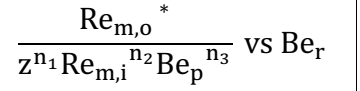 & 0.455 & 0.250 & -0.029 \\
\hline 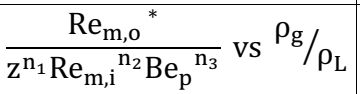 & 0.003 & 0.035 & 0.235 \\
\hline
\end{tabular}

Table 3. Correlation coefficients and gradients for the final iteration.

\begin{tabular}{|c|c|c|c|}
\hline Dimensionless group & $\mathbf{R}^{2}$ & $\mathbf{a}$ & B \\
\hline$\frac{\mathrm{Re}_{\mathrm{m}, \mathrm{o}}{ }^{*}}{0.934 \mathrm{Re}_{\mathrm{m}, \mathrm{i}}{ }^{-0.061} \mathrm{Be}_{\mathrm{r}}{ }^{0.249}} \mathrm{vs} \mathrm{z}$ & 0.882 & -0.018 & 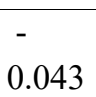 \\
\hline$\frac{\operatorname{Re}_{\mathrm{m}, \mathrm{o}}{ }^{*}}{0.934 \mathrm{z}^{-0.076} \mathrm{Be}_{\mathrm{r}}{ }^{0.249}} \mathrm{vs} \mathrm{Re}_{\mathrm{m}, \mathrm{i}}$ & 0.933 & -0.027 & -0.056 \\
\hline 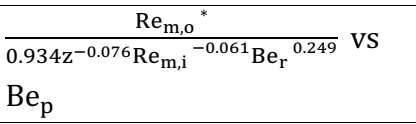 & 0.038 & 0.068 & -0.595 \\
\hline$\frac{\operatorname{Re}_{\mathrm{m}, \mathrm{o}}{ }^{*}}{0.934 \mathrm{z}^{-0.076} \operatorname{Re}_{\mathrm{m}, \mathrm{i}}{ }^{-0.061}} \mathrm{vs} \mathrm{Be}_{\mathrm{r}}$ & 0.865 & 0.276 & -0.283 \\
\hline $\begin{array}{l}\text { Final model prediction } \\
\qquad v_{\mathrm{m}, \text { model }} v s v_{\mathrm{m} \text {,actual }}\end{array}$ & 0.94 & 0.70 & 0.018 \\
\hline
\end{tabular}

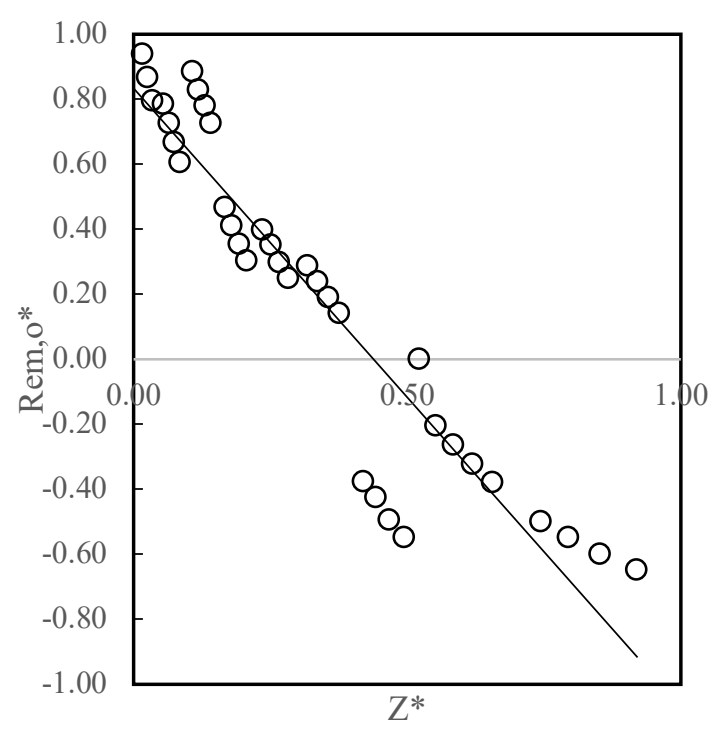

Figure 1. Mixture Reynolds number versus choke opening $(\mathrm{a}=-0.076, \mathrm{~b}=$ $2.32, \mathrm{R}^{2}=0.486$ ).

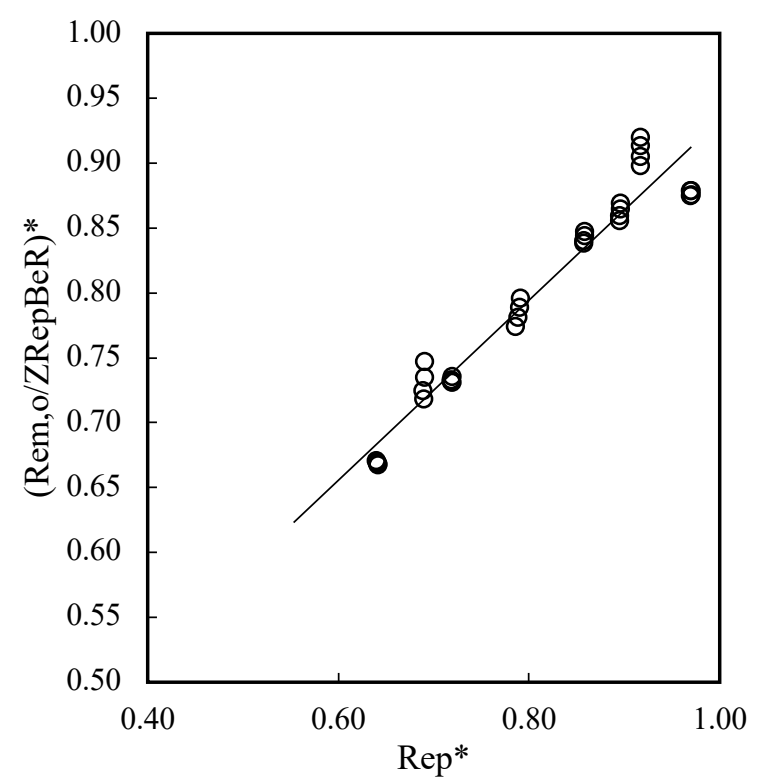

Figure 2. Combined dimensionless group vesus Reynolds number in the pipleine $\left(\left(\mathrm{a}=-0.056, \mathrm{~b}=-0.027, \mathrm{R}^{2}=0.938\right)\right.$. 


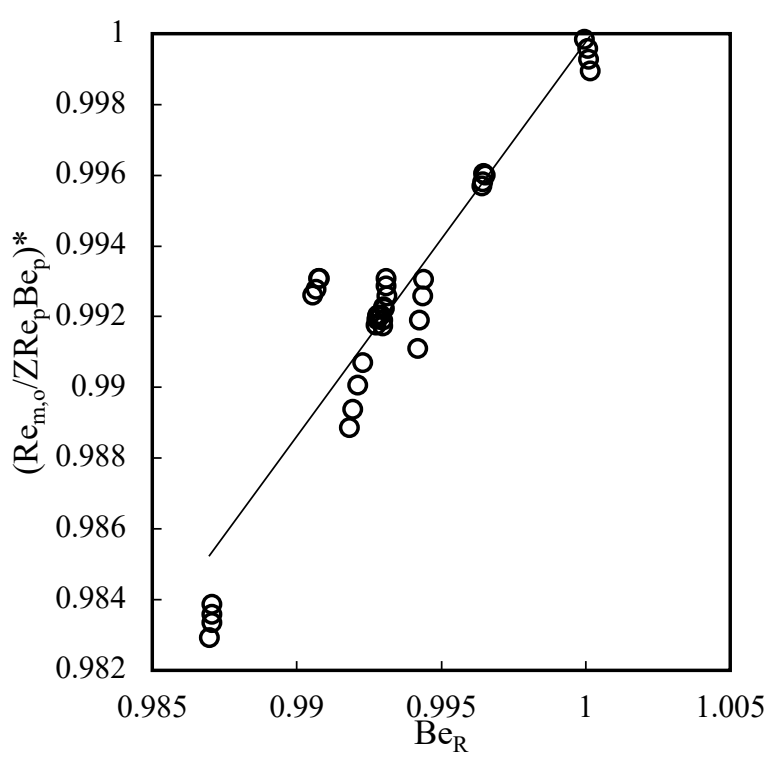

Figure 3. Combined dimensionless group vesus Bejan number in riser $(\mathrm{a}=$ $0.275, \mathrm{~b}=-0.28, \mathrm{R}^{2}=0.865$ ).

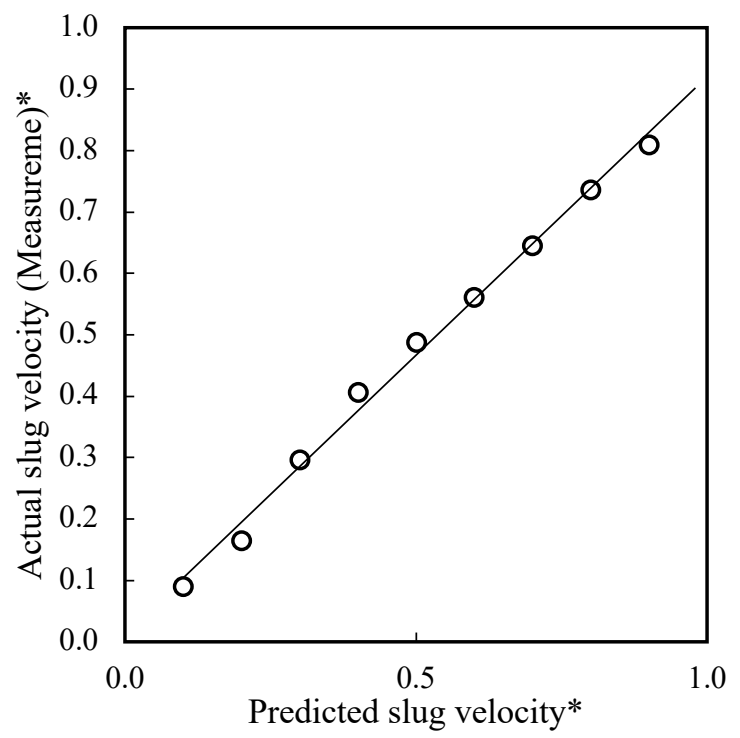

Figure 4. Slug flow velocity comparison between measurements and model predictions $\left(\mathrm{a}=0.995, \mathrm{~b}=0, \mathrm{R}^{2}=0.766\right)$.

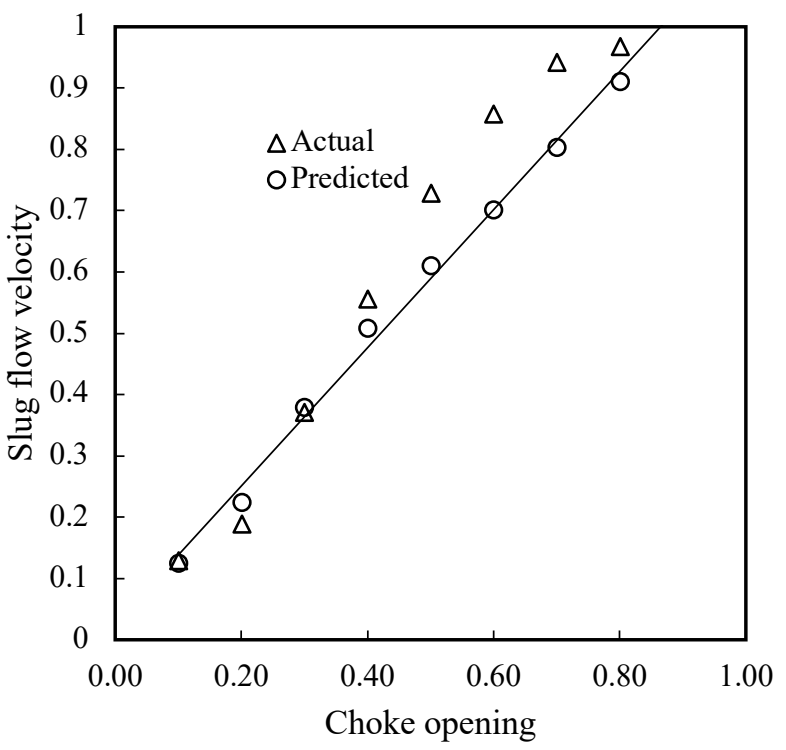

Figure 5. Slug flow velocity predictions from new correlation with choke opening $\left(a=0.6, b=0.6, R^{2}=0.87\right)$.

\section{ACKNOWLEDGMENT}

The authors gratefully acknowledge Equinor Canada Ltd, Natural Sciences and Engineering Research Council of Canada (NSERC), and School of Graduate Studies at Memorial University for their financial support,

\section{REFERENCES}

[1] Buckingham, E. (1914). On physically similar systems; illustrations of the use of dimensional equations. Physical Review, 4(4), 345.

[2] Igbokwe, L., Severe Slugging with Multiphase Fluid Transport and Separation in Subsea Pipelines, PhD Thesis, Department of Process Engineering, Memorial University, St. John's, NL Canada, 2020

[3] Naterer, G. F. (2018), Advanced Heat Transfer, 2nd Edition, CRC Press, Boca Raton, FL.

[4] Pedersen, S., Durdevic, P., and Yang, Z. (2017). Challenges in slug modeling and control for offshore oil and gas productions: A review study. International Journal of Multiphase Flow, 88, 270-284.

[5] Taitel, Y., Vierkandt, S., Shoham, O., and Brill, J. (1990). Severe slugging in a riser system: experiments and modeling. International Journal of Multiphase Flow, 16(1), 57-68. 